\title{
Magnetic resonance imaging confirmed clinical diagnosis of amyoplasia in two infants with arthrogryposis multiplex congenita
}

\author{
Ariam Diaz, Dominic Sia, Valerie May G Sia, Evelyn Erickson, \\ Sergey Prokhorov, Menachem Gold
}

\begin{abstract}
Introduction: We present two cases of arthrogryposis multiplex congenita (AMC) with involvement of the lower extremities. In both cases amyoplasia was confirmed by a magnetic resonance imaging (MRI). The degree of amyoplasia correlated with the severity of arthrogryposis and determined the child's prognosis. Case Series: Case 1 was a 16-monthold male child with prenatally diagnosed Klinefelter syndrome was born at 36 weeks gestation. Brain MRI was reported as normal. Joint rigidity was detected in upper and lower extremities. Amyoplasia was suspected at nine months of age since the lower limb muscles were hardly palpable. Case 2 was a $51 / 2$-monthold female child and the first child of nonconsanguinous parents was noticed to have rigid right calcaneovalgus and left equinovarus feet deformities as well as knee rigidity with limitation of knee extension. Bilateral hip displacement was also diagnosed. Absence of muscles on thigh palpation prompted MRI study. Conclusion: Although amyoplasia is the most common type of arthrogryposis multiplex congenita, muscle underdevelopment in these
\end{abstract}

Ariam Diaz ${ }^{1}$, Dominic Sia1, Valerie May G Sia1, Evelyn Erickson ${ }^{1}$, Sergey Prokhorov ${ }^{1}$, Menachem Gold ${ }^{2}$

Affiliations: ${ }^{1}$ Department of Pediatrics, Lincoln Medical \& Mental Health Center, Bronx, NY, United States; 2Department of Radiology, Lincoln Medical \& Mental Health Center, Bronx, NY, United States.

Corresponding Author: Sergey Prokhorov, MD Department of Pediatrics, Lincoln Medical \& Mental Health Center, 234 East 149th Street, Bronx, New York, USA-10451; Ph: 718594-6501; Fax: 718-579-4700; Email: sproxy113@gmail.com

Received: 03 November 2011

Accepted: 27 March 2012

Published: 01 January 2013 patients remains puzzling for pediatric practitioners. Amyoplasia congenita is usually symmetrical and involves either all extremities or selectively only the lower or upper extremities. Absence of muscle groups on MRI confirms diagnosis of amyoplasia. Early recognition of amyoplasia in children with arthrogryposis multiplex congenita can help in tailoring their treatment and prognosis.

Keywords: Amyoplasia, Arthrogryposis multiplex congenita (AMC)

$* * * * * * * * *$

Diaz A, Sia D, Sia VMG, Erickson E, Prokhorov S, Gold M. Magnetic resonance imaging confirmed clinical diagnosis of amyoplasia in two infants with arthrogryposis multiplex congenita. International Journal of Case Reports and Images 2013;4(1):7-10.

$* * * * * * * * *$

doi:10.5348/ijcri-2013-01-248-CS-2

\section{INTRODUCTION}

Arthrogriposis multiplex congenita (AMC) affects about $1 / 3000$ birth in North America [1]. Amyoplasia $(\mathrm{A}=$ no, myo=muscle and plasia $=$ growth $)$ is the most common type of arthrogryposis seen clinically [2]. We present two cases of arthrogryposis multiplex congenita with prominant involvement of the lower extremities. In both cases amyoplasia was confirmed by magnetic resonance imaging (MRI) of the thighs. The degree of amyoplasia correlated with the severity of arthrogryposis and determined the child's prognosis. MRI may be helpful in the differentiation between amyoplasia and other congenital myopathies and muscular dystrophies [3]. 


\section{CASE SERIES}

Case 1: The patient was a 16-month-old male baby, prenatally diagnosed with Klinefelter syndrome born at 36 weeks gestation from a non-consanguineous marriage. The delivery was by emergency cesarean section due to fetal heart rate deceleration. Apgar score was 1,2 and 5 at 1,5 and 10 minutes. During the first two days of life the baby developed seizures. Brain MRI was reported as normal. Joint contractures were recognized on the fourth day of the baby's life. Amyoplasia was suspected at nine months of age since the lower limb muscles were barely palpable. MRI of the thigh revealed paucity of muscles (Figures 1 and 2). On examination, the baby presented with microcephaly (head circumference $44 \mathrm{~cm},<2 \%$ ), bilateral epicanthus and clinodactily of the fifth fingers. The child was able to hold sitting position, however, he was not able to sit up by himself. There was stiffness in the wrists with limitation of wrist extension. Hand grasp was weak. The child was unable to hold a spoon. Hip abduction was limited to $30^{\circ}$. Knee flexion was limited to $90^{\circ}$. There was also equinovarus feet deformity. The child moved the upper extremities well, but only slightly raised the extended lower extremities and minimally flexed them at the knees. He supported his weight on his legs when in standing position with support. In the lower

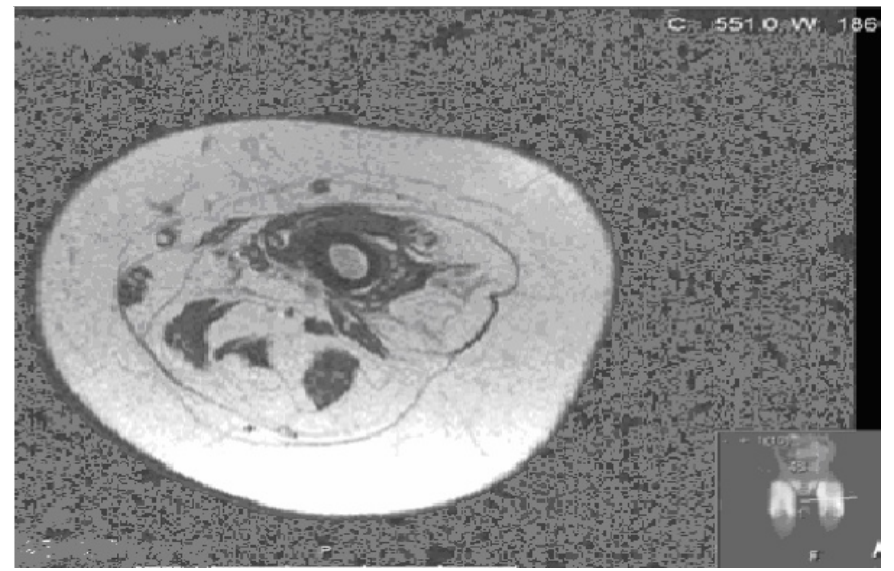

Figure 1: Magnetic resonance imaging of the thigh revealed paucity of muscles in patient from Case 1 .

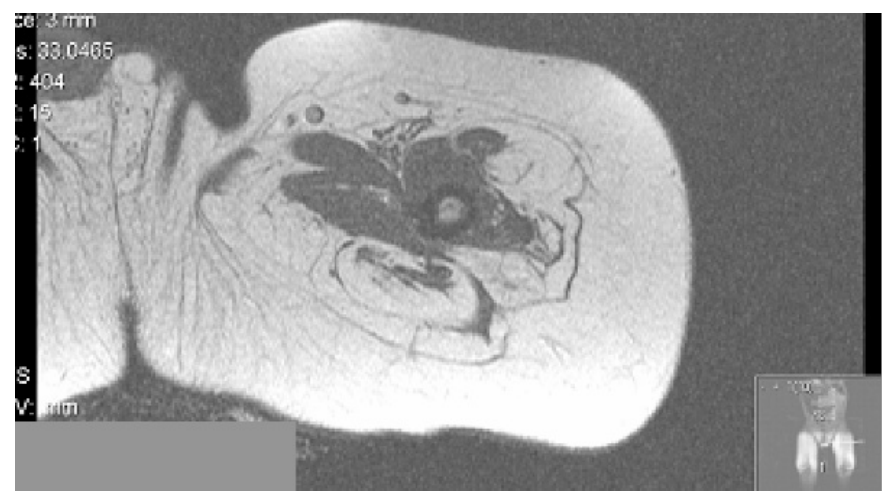

Figure 2: Another magnetic resonance imaging of the thigh revealed paucity of muscles in patient from Case 1 . extremities only hip adductors were slightly palpable. Gluteus muscle contraction was evident. Biceps, brachioradial and knee reflexes were normal. Plantar response was down-going. There was no deficiencies in sensation to the touch and pinprick.

Case 2: A $5 \frac{1}{2}$-month-old female was the first child of non-consanguinous parents was born after full term uneventful pregnancy by normal vaginal delivery. Apgar score was 9 and 9 at 1 and 5 minutes. Birth weight was $3.8 \mathrm{~kg}$. At birth the baby was noticed to have rigid right calcaneovalgus and left equinovarus feet deformities, as well as knee rigidity with limitation of knee extension. Bilateral hip displacement was also diagnosed. Current neurological examination revealed peripheral right facial palsy and torticollis due to shortened right sternocleidomastoid muscle. The upper extremities were without any neurological deficiencies. The lower extremities were in fixed frog-leg position with rigid feet deformity. Active movements manifested with very slight hip adduction and minimal toe movements. The muscles were not detectable on leg palpation. Knee and ankle jerks were absent. Plantar response was mute. Sensation to pinprick and touch was preserved throughout. The anus was closed and anal blink reflex was brisk. The baby demonstrates good head control, raising the head and chest while being in prone position; grasping and transferring an object from one hand to another with good visual attention to the grasped object. The baby had positive stranger anxiety. MRI of the hips showed absence of musculature with preserved fascial planes, vessels, and adipose tissue (Figure 3).

As part of management, both patients underwent surgical correction of their tulip equinovarus. On followup at three years of age, their neurological evaluation showed that they both were able to sit up, but not stand up. Only the first patient was able to stand with support.

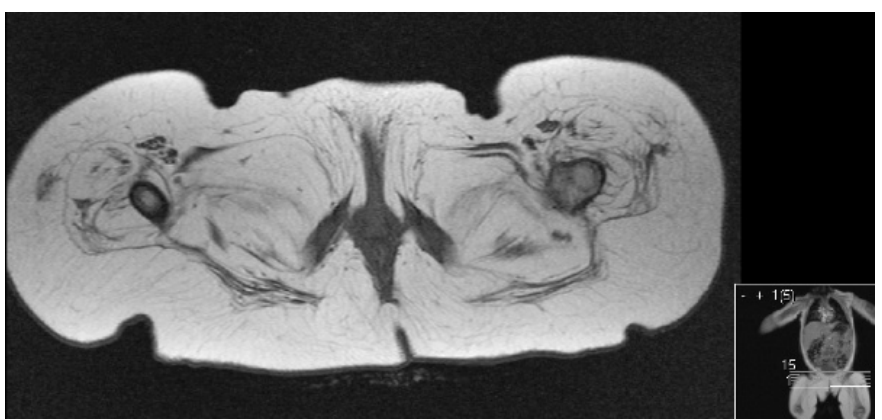

Figure 3: Magnetic resonance imaging of the hips showed absence of musculature in patient from Case 2.

\section{DISCUSSION}

Despite the fact that amyoplasia is the most common type of arthrogryposis multiplex congenital [2, 3], recognition of considerable muscle underdevelopment in these patients remains surprising and puzzling for pediatric practitioners. Amyoplasia congenita is usually 
symmetrical and involves either all extremities or selectively only the lower or upper extremities [4]. The muscle mass of the limbs with arthrogryposis is diminished. In a study by Hall et al., histologic examination of muscles showed the replacement of muscle with fibrofatty scar tissue [5]. Studies of spinal cord and muscles in patients with amyoplasia suggests two possible affected areas: either anterior horn cells or muscles [6, 7]. Intrauterine vascular insult of spinal motor neurons or limb muscles was hypothesized [8, 9]. It is also known that arthrogryposis can be a genetically heterogeneous disorder as for instance, in distal arthrogryposis. Our first case can be considered as an arthrogryposis with all limb involvement even though the wrist stiffness is the only finding in the upper extremities. The presence of a brisk knee jerk does not support the spinal origin of amyoplasia. Decrease of femoral muscle mass on thigh MRI is significant, but the leg extensors remained strong enough to bear body weight. Klinefelter syndrome diagnosed in this child most likely does not have any causal relation with the amyoplasia. Our second case presented with arthrogryposis only in the lower extremities. MRI showed absence of femoral muscles bilaterally. Congenital facial palsy in this child is considered as a partial Moebius anomaly, which is a known comorbidity of amyoplasia congenita.

Muscle weakness and multiple joint contractures in both patients could have suggested congenital muscle dystrophy (CMD) and congenital myopathy (CM). However, MRI revealed absence of whole muscle groups, with fibrofatty tissue instead and preserved fibrous planes. In patients with CMD and CM, MRI shows peculiar selectivity of muscle involvement, with decreased muscle volume and abnormal MRI signals from the muscles [3].

\section{CONCLUSION}

Early recognition of amyoplasia with an assessment of muscle underdevelopment via limb magnetic resonance imaging in children with arthrogryposis multiplex congenita elucidates their clinical presentation and can help in tailoring their treatment and in the prognostication of the degree of their future disability.

$* * * * * * * * *$

\section{Acknowledgements}

Evelyn Erickson, MD - Technical contributor

\section{Author Contributions}

Ariam Diaz - Conception and design, Acquisition of data, Analysis and interpretation of data, Drafting the article, Critical revision of the article, Final approval of the version to be published

Dominic Sia - Conception and design, Acquisition of data, Analysis and interpretation of data, Drafting the article, Critical revision of the article, Final approval of the version to be published

Valerie May G Sia - Conception and design, Acquisition of data, Analysis and interpretation of data, Drafting the article, Critical revision of the article, Final approval of the version to be published

Evelyn Erickson - Acquisition of data, Drafting the article, Critical revision of the article, Final approval of the version to be published

Sergey Prokhorov - Conception and design, Acquisition of data, Analysis and interpretation of data, Drafting the article, Critical revision of the article, Final approval of the version to be published

Menachem Gold - Conception and design, Acquisition of data, Analysis and interpretation of data, Drafting the article, Critical revision of the article, Final approval of the version to be published

\section{Guarantor}

The corresponding author is the guarantor of submission.

\section{Conflict of Interest}

Authors declare no conflict of interest.

\section{Copyright}

(C) Ariam Diaz et al. 2013; This article is distributed under the terms of Creative Commons Attribution 3.0 License which permits unrestricted use, distribution and reproduction in any means provided the original authors and original publisher are properly credited. (Please see www.ijcasereportsandimages.com /copyright-policy.php for more information.)

\section{REFERENCES}

1. Hall JG. Arthrogryposis. In: Roger E Stevenson, Hall JG, Goodman RM (Eds). Human Malformations and Related Anomalies. Oxford monograph on medical genetics 1997.No.27; VolII:798-804.

2. Hall JG. Genetic Aspects of Arthrogryposis. Clinical Orthopedics and Related Research 1985 Apr;(194):44-53.

3. Mercuri E, Jungbluth H, Muntoni F. Muscle imaging in clinical practice: diagnostic value of muscle magnetic resonance imaging in inherited neuromuscular disorders. Curr Opin Neurol 2005;18(5):526-37.

4. Hall JG. Arthrogryposis multiplex congenital: etiology, genetics, classification, diagnostic approach, and general aspects. J Pediatr Orthop B 1997;6(3):159-66.

5. Sells JM, Jaffe KM, Hall JG. Amyoplasia, the most common type of arthrogryposis: the pathophysiology for good outcome. Pediatr 1996:97(2):225-31.

6. Brown LM, Robson MJ, Sharrard WJ. The pathophysiology of arthrogryposis multiplex congenita neurologica. J Bone Joint Surg Br 1980 Aug;62(3):291-6.

7. Drachan DB, Banket BQ. Arthrogryposis maltiplex congenital. Arch Neurol 1991;5:77-933. 
8. Reid CO, Hall JG, Anderson C, et al. Association of amyoplasia with gastroschisis, bowel atresia, and defects of the muscular layer of the trunk. Am J Mede Genet 1986;24(4):701-10.
9. Robertson WL, Glinski LP, Kirkpatrick SJ, Pauli RM. Further evidence that arthrogryposis multiplex congenital in the human is caused by an intrauterine vascular accident. Teratology 1992 Apr;45(4):345-1.
Access full text article on other devices

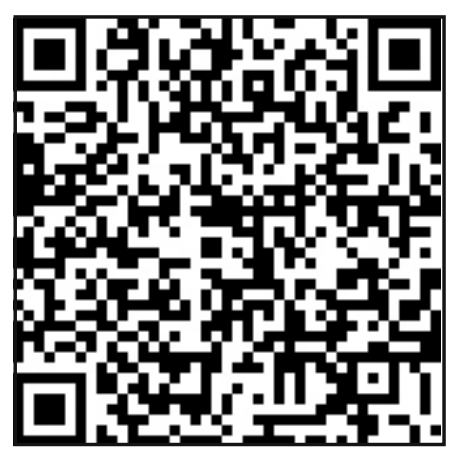

Access PDF of article on other devices

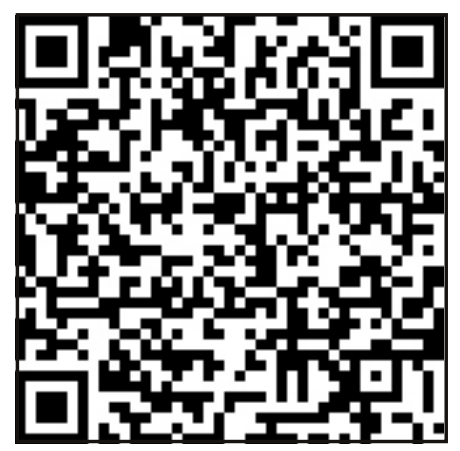

